\title{
ANÁLISE DA EXPANSÃO DA GERAÇÃO ELÉTRICA FOTOVOLTAICA E EMISSÕES DE DIÓXIDO DE CARBONO
}

\author{
C.R. Paulista ${ }^{1}$; T.S. Machado ${ }^{1,2}$; J.J.A. Rangel ${ }^{1,2^{*}}$ \\ 1 Instituto Federal Fluminense (IFF), 28030-131, Campos dos Goitacazes - RJ, Brasil \\ 2 Universidade Cândido Mendes (UCAM-Campos), 28030-335, Campos dos Goitacazes - RJ, Brasil \\ *joao.rangel@ucam-campos.br
}

Artigo submetido em 20/02/2017 e aceito em 29/04/2017

\section{RESUMO}

Esse trabalho tem o objetivo de analisar a expansão da energia elétrica fotovoltaica e dados recentes do comportamento das emissões de $\mathrm{CO}_{2}$ no Brasil e alguns países selecionados. Os dados foram coletados em diferentes bases como: Agência Internacional de Energia, Ministério de Minas e Energia e Empresa de Pesquisa Energética, além de artigos da área. A Identidade de Kaya foi utilizada como base para avaliar as emissões de $\mathrm{CO}_{2}$. Como resultado, percebeu-se o domínio da Alemanha e Itália no setor de geração fotovoltaica, com fortes investimentos no desenvolvimento e disseminação dessa tecnologia. O Brasil apresentou uma matriz energética de baixo carbono, porém com tendência de aumento de emissões per capita ao longo dos anos. Foi verificado o efeito de desacoplamento entre as emissões de gases do efeito estufa e o desenvolvimento econômico em escala mundial. Percebeu-se que tal fenômeno tende a se intensificar no passo em que as tecnologias de energias renováveis atinjam patamares mais altos de utilização.

\section{ANALYSIS ON THE PHOTOVOLTAIC ELECTRICITY GENERATION EXPANSION AND CARBON DIOXIDE EMISSIONS}

\begin{abstract}
This paper aims to analyze the photovoltaic electricity energy expansion and recent data about the behavior of the $\mathrm{CO}_{2}$ emissions in Brazil and other selected countries. Data were collected from different bases as International Energy Agency (Agência Internacional de Energia), Ministry of Energy and Mines (Ministério de Minas e Energia), Research Electric Company as well as other papers in the field. Kaya Identity was applied as basis in order to evaluate the $\mathrm{CO}_{2}$ emissions. As a result, it could be seen a clear domain of Germany and Italy in
\end{abstract}

the photovoltaic generation sector, with high investments in the development and dissemination of that technology. Brazil presented an energetic matrix of low carbon but with a tendency to increase emissions per capita throughout the years. The effect of decoupling between the greenhouse gas emissions and the largescale economic development was checked. It was realized that that phenomenon tends to intensify it since renewable energy technologies get higher levels of use.

KEYWORDS: carbon emissions, energy efficiency, decoupling effect. 


\section{INTRODUÇÃO}

Em recente trabalho, Abramovay (2014) chamou a atenção para o fato de estar ocorrendo duplicação da oferta de energia gerada por fontes renováveis, numa faixa temporal entre 2008 e 2012, em alguns países mais desenvolvidos. No mesmo trabalho, o autor destacou que a energia gerada por fonte solar direta, a fotovoltaica (FV), especificamente, foi quinze vezes maior em 2013 do que em 2008. Além disso, foram contabilizadas quedas de preço dos painéis solares, mostrando um decrescimento de 65\%, comparando o ano de 2012 com os dezoito meses anteriores.

Essa queda do preço dos painéis FV pode ser associada ao imperativo ecológico em que se vive nos últimos anos. Didoné et al. (2014) mostraram que 44\% da matriz energética brasileira é composta por energias renováveis. Em outro trabalho, Gaviria et al. (2013) destacaram que o Brasil possui grande potencial de geração de energia renovável por fonte solar direta. Eles atentam para o fato de se tratar de um país tropical e com grande disponibilidade de irradiação solar. Do ponto de vista da comercialização, Goldemberg (2015) afirmou que, para haver uma expansão mais rápida da produção de energia por fontes renováveis no Brasil, deve-se acontecer mudanças nos processos de leilões, que atualmente são realizados por fonte, separadamente. Na visão de Sachs (2007), a história da humanidade foi marcada por revoluções energéticas sucessivas, não por escassez de recursos, mas sim por uma visão voltada para fontes de menor custo e/ou maior qualidade, como a que parece estar havendo com a geração FV.

Assim, diante da perspectiva que se apresenta com relação ao crescimento da geração FV, este trabalho possui o objetivo de analisar a evolução da geração de energia elétrica FV em âmbito mundial, selecionando alguns países importantes no setor energético e econômico. É também matéria deste trabalho avaliar a emissão de $\mathrm{CO}_{2}$ no Brasil ao longo dos anos, através da análise da Identidade de Kaya. Por fim, é explanada a perspectiva dos sistemas FV no país, trazendo informações sobre o potencial de geração residencial de energia elétrica renovável.

As informações contidas neste estudo foram coletadas na base de dados da Agência Internacional de Energia (IEA - International Energy Agency) além de outros dados disponibilizados on-line. Foram também utilizadas fontes brasileiras, tais como o Ministério de Minas e Energia (MME, 2014) e a Empresa de Pesquisa Energética (EPE, 2012).

Por fim, o trabalho que se apresenta foi organizado da seguinte forma. A seguir é apresentada a definição da decomposição matemática de Kaya. Posteriormente, foram tecidos comentários sobre recentes trabalhos com foco na geração FV, com estudos de caso aplicados no Brasil. Em seguida, foram desenvolvidos gráficos para servirem de base na discussão do cenário global, no que tange às emissões de $\mathrm{CO}_{2}$ e geração de energia renovável. Na sequência, a situação brasileira foi colocada em pauta. Foram discutidas as perspectivas futuras quanto às emissões de dióxido de carbono e desenvolvimento econômico mundial. Por fim, compilou-se algumas considerações, compondo a seção conclusiva do trabalho.

\section{DEFINIÇÕES E MÉTODO}

\subsection{Identidade de Kaya}

Yoichi Kaya (1997) desenvolveu uma decomposição matemática cujo objetivo foi de quantificar as emissões de dióxido de carbono nas gerações futuras. Com esse recurso, tenta-se convergir para um cenário de adoção de novas tecnologias que possuam menor potencial poluidor (ALVIM; SANTIN, 2008b). Sendo assim, foi desenvolvida a seguinte Equação: 


$$
C=P \times \frac{P I B}{P} \times \frac{E}{P I B} \times \frac{C}{E}
$$

Onde:

$\mathrm{C}$ : Emissões de dióxido de carbono (MtCO2)

P: População

PIB: Produto Interno Bruto (1 bilhão de dólares americanos em 2005)

E: Energia (Mtep)

Tep: tonelada equivalente de petróleo

Disso, infere-se que:

PIB/P: PIB per capita (bilhões de dólares americanos em 2005/capita)

E/PIB: Intensidade energética (tep/mil dólares americanos em 2005)

$\mathrm{C} / \mathrm{E}$ : Intensidade de dióxido de carbono (tCO2/tep)

Essa metodologia traz consigo o conceito de que a variação nos valores de emissões de CO2 tem relação íntima com a variação populacional, intensidade energética, intensidade de emissão de dióxido de carbono, e crescimento econômico.

Lucon e Goldemberg (2009) afirmaram que a intensidade energética representa o consumo de energia por PIB no país. Vale salientar que tanto a intensidade energética quanto a intensidade de dióxido de carbono têm conexão com a tecnologia utilizada no período considerado. Alvim e Santin (2008a) mostraram que o consumo de energia - menor consumo energético per capita - tende a ser otimizado com os avanços tecnológicos, além de se reduzir as emissões de gases do efeito estufa (GEE). Já a intensidade de dióxido de carbono tem conexão estreita com a matriz energética do país estudo.

\subsection{Dados recentes em geração FV}

Diversos estudos recentes mostram o interesse na área de geração FV. Dentre eles, foram destacados alguns estudos de caso aplicados em território brasileiro.

Gaviria et al. (2013) estudaram diversas fachadas de edifícios brasileiros, a fim de calcular o potencial de geração FV dos mesmos, através de simulações computacionais com o software Rhinoceros, para a criação dos modelos. O principal objetivo do trabalho consistiu em analisar diferentes tipologias urbanas brasileiras, para então se definir qual delas apresenta melhor potencial de instalação de painéis $\mathrm{FV}$, seja em posição vertical ou horizontal. Eles ressaltaram que a variável altura é um parâmetro fundamental no aproveitamento solar das edificações, quando elas são analisadas separadamente.

Didoné et al. (2014) avaliaram o potencial de edifícios brasileiros se tornarem edifícios energia zero (EEZ), com a instalação de módulos FV incorporados em sua estrutura. Eles utilizaram o EnergyPlus e Daysim como softwares de apoio nas fases de simulação. Foram considerados três modelos de edificação, quando ao consumo de energia: caso protótipo, otimizado e energia zero. Os autores destacaram a promissora alternativa de se utilizar janelas com fotovoltaico semitransparente para a geração FV, que, na simulação, resultaram em $21 \%$ de geração em Florianópolis e $11 \%$ em Fortaleza. 
Lange (2012) propôs uma metodologia de mapeamento da área potencial de telhados para fins de aproveitamento energético, a nível de macrorregião, estado e município. $\mathrm{O}$ autor calculou o potencial FV do município do Rio de Janeiro. Ele considerou que o procedimento adotado se mostrou eficiente para se comparar o potencial FV entre estados e municípios.

Di Santo et al. (2015) investigaram sete smart grids existentes no Brasil, denotando a atenção que o país tem dado à implantação de tecnologias inteligentes que integram outras áreas automação e telecomunicações, por exemplo - à geração FV, otimizando os processos.

\subsection{Método}

Este trabalho foi elaborado a partir de dados obtidos em consultas nas bases de dados do MME, EPE e IEA. Foram selecionados cinco países a serem analisados, além do Brasil. Após as buscas, foram criados gráficos com o objetivo de demonstrar o comportamento das curvas relativas à tecnologia $\mathrm{FV}$, eólica, e emissões de $\mathrm{CO} 2$, nos países selecionados. A Identidade de Kaya foi utilizada como ferramenta de análise das emissões de GEE. As perspectivas futuras foram analisadas à luz do efeito de desacoplamento entre o PIB mundial e as emissões de dióxido de carbono.

\section{RESULTADOS E DISCUSSÃO}

\subsection{Comparativos mundiais}

Os países analisados nesse artigo foram os Estados Unidos, Alemanha, Itália, Japão e Espanha. Eles compõem o grupo dos países mais desenvolvidos no aproveitamento da energia solar (MACHADO; MIRANDA, 2015). Os Estados Unidos e o Japão estavam entre os cinco maiores emissores de dióxido de carbono do mundo em 2013, conforme dados divulgados no relatório sobre emissões de $\mathrm{CO}_{2}$ por queima de combustíveis fósseis (IEA, 2015). A Alemanha, Itália e Espanha se destacam no cenário mundial de investimento em fontes renováveis, dominando o mercado europeu nessa vertente (EPIA, 2014).

A variação percentual de geração elétrica por sistemas FV nesses países, de 2012 para 2013, pode ser observada na Figura 1, e calculada pela Equação 2. A nomenclatura das variáveis representa os valores de energia FV acumulada nos respectivos anos subscritos.

$$
\Delta \%=\frac{F V_{2013}-F V_{2012}}{F V_{2012}}
$$

Nota-se claramente o destaque do Japão nos investimentos para o desenvolvimento dessa tecnologia nos últimos anos. Ele dobrou a sua capacidade de geração nessa faixa de tempo. Pode-se perceber a característica marcante tanto deste país quanto dos Estados Unidos em promover altos desenvolvimentos tecnológicos num curto espaço de tempo, em comparação com os outros países analisados. A Alemanha, apesar de não ter mostrado grandes progresso entre 2012 e 2013, possui aproximadamente o dobro de capacidade instalada dos Estados Unidos, no que se refere à geração elétrica FV. 
Figura 1 - Capacidade instalada de energia elétrica FV (barras) e variação percentual (linhas).

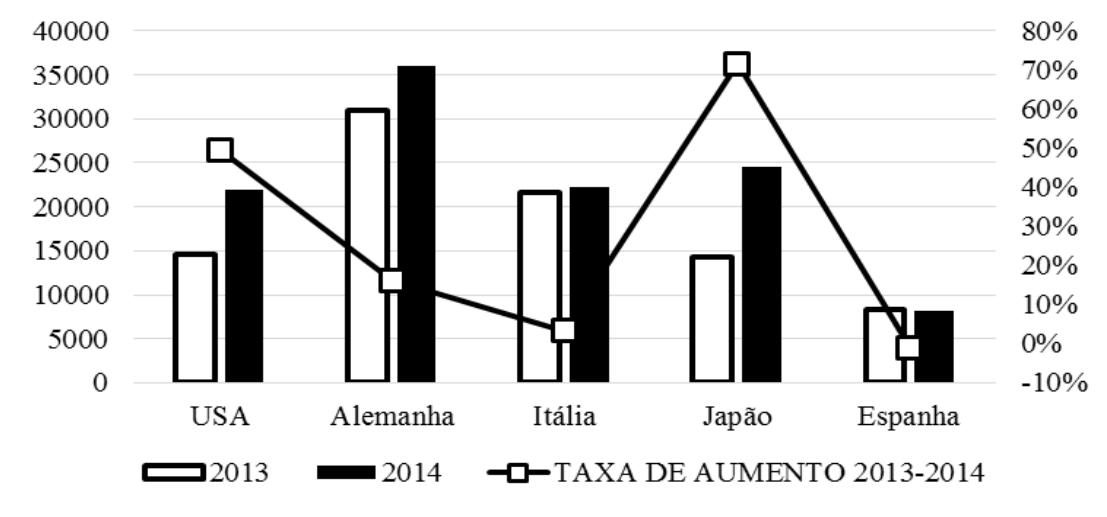

Fonte: Elaboração própria.

$\mathrm{O}$ aumento da magnitude de energia solar FV gerada nesses países pode ser visto na Figura 2. Apesar da IEA fornecer dados desde 1990, considerou-se apenas os anos a partir de 2000, momento em que os valores passaram a se tornar mais expressivos. Conforme pode-se observar nesta Figura, a Alemanha e Itália dominam o setor. O Brasil não aparece nessa Figura por não ter quantidade de energia gerada suficiente na mesma escala dos outros países. No entanto, um cenário diferente pode ser vislumbrado na análise da energia eólica, de acordo com a Figura 3. O Brasil aparece no contexto eólico, ultrapassando a geração produzida no Japão em 2012. Nota-se uma semelhança de perfil entre as curvas de energia FV e eólica, com a maior diferença apresentada nas cargas em gigawatts-hora (GWh).

Figura 2 - Geração de energia FV.

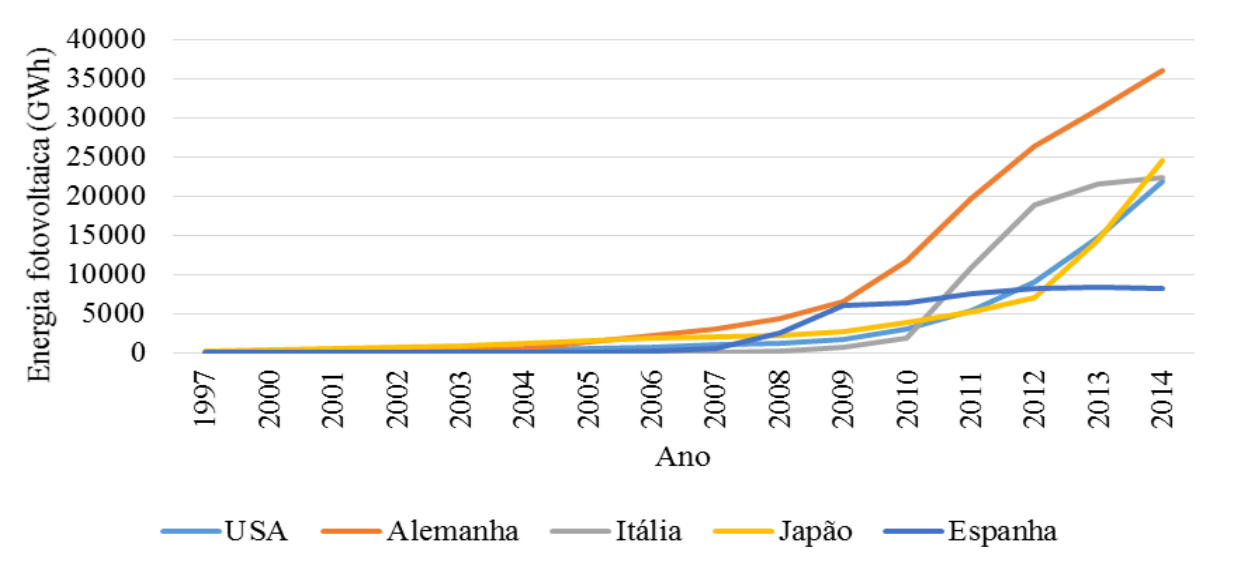

Fonte: Elaboração própria. 
Figura 3 - Geração de energia eólica.

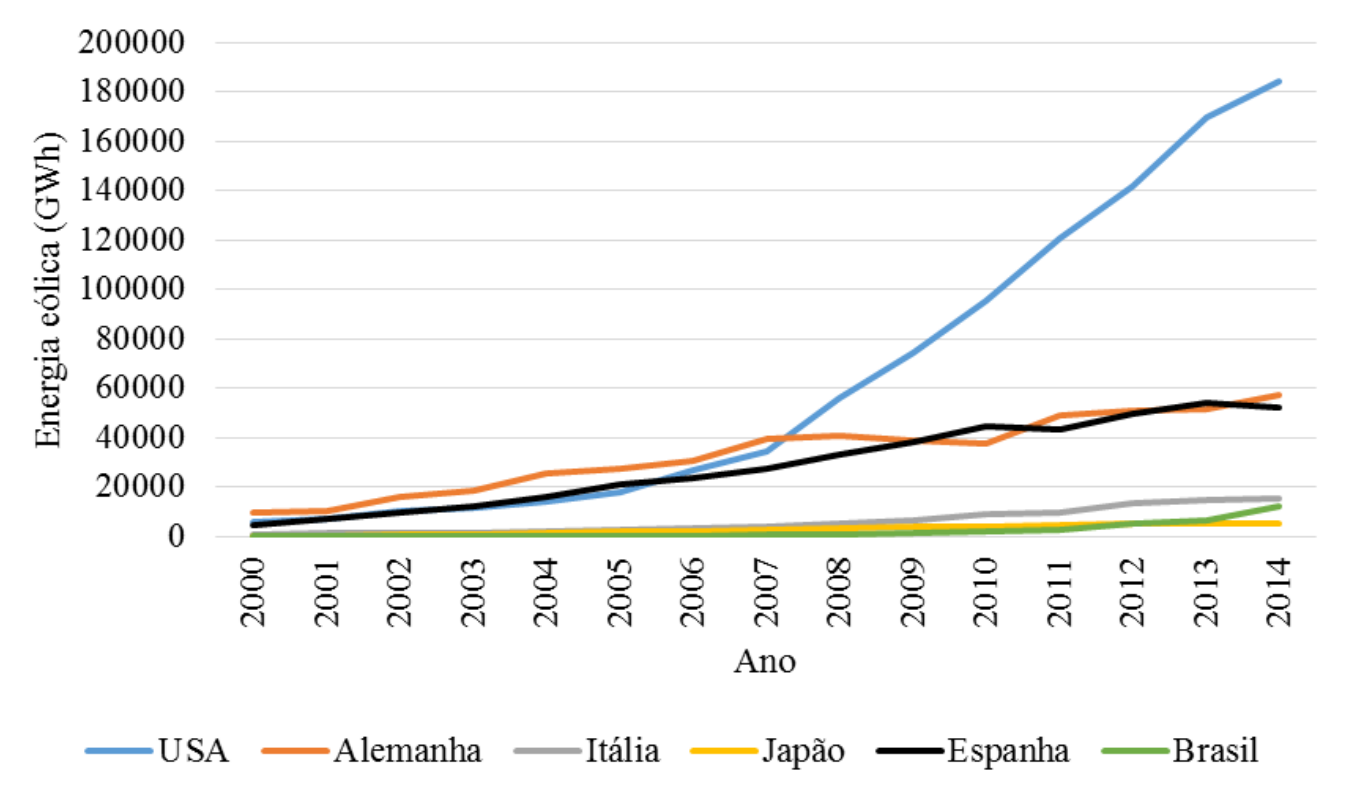

Fonte: Elaboração própria.

O desenvolvimento da Espanha no setor energético renovável deve ser considerado. Percebe-se nas Figuras 2 e 3 que houve uma expansão de investimento nas fontes de energia eólica e FV, tanto por parte desse país quanto da Alemanha, entre 2007 e 2008. Ambos utilizaram um incentivo chamado feed-in-tariff, que são contratos de longo prazo com os produtores de energias não-fósseis, a fim de incentivar a aceleração do desenvolvimento das tecnologias voltadas ao setor renovável. Nesse período, o aumento de geração FV mundial foi de $80 \%$. (MAABEN; RÜBSAMEN; PEREZ, 2011).

Outros pontos de cruzamento das curvas trazem informações importantes. Exatamente na época em que ocorreu a grande crise econômica de 2008, a Alemanha reduziu seu potencial de energia eólica. No entanto, a mesma expandiu seus investimentos em tecnologia FV, superando diversas potências mundiais. Acontece que, em 2011, o fornecimento de energia elétrica gerada por sistemas FV, por parte tanto da Alemanha quanto da Itália, possuía os maiores custos para o consumidor (EPE, 2012). O paralelismo das curvas representativas desses países comprova o investimento proporcional na mesma tecnologia entre 2010 e 2012, conforme mostrado na Figura 4. Daí os altos investimentos para o desenvolvimento da tecnologia na época, visto a oportunidade de maiores lucros com a alta do valor. Somando a porção de energia FV gerada na Alemanha e Itália, calcula-se um total de 59\% do total em relação aos outros três países, como mostrado na Figura 5. 
Figura 4 - Investimento em tecnologia FV proporcional entre Alemanha e Itália.

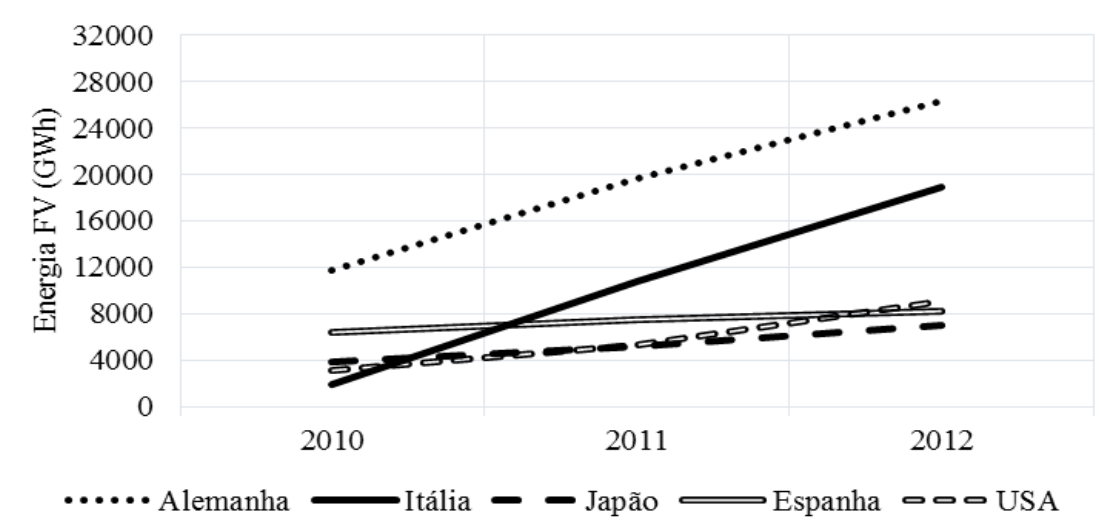

Fonte: Elaboração própria.

Figura 5 - Geração elétrica FV nos países de referência, em 2013.

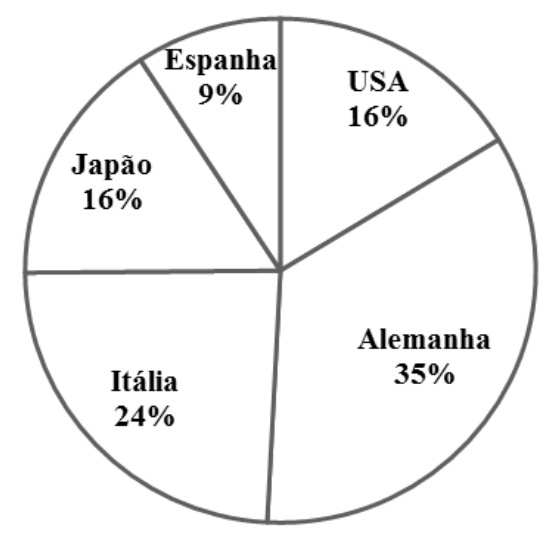

Fonte: Elaboração própria.

\subsection{Identidade de Kaya alemã e norte-americana}

Foi realizada uma análise da Alemanha e dos Estados Unidos, com aplicação da Identidade de Kaya. O comportamento ascendente ou descendente das curvas indicam o estado do país num determinado ano em relação ao ano-base de 1990 (índice $=1$ ). A abordagem compreendeu o período de 1990 a 2014.

A abordagem relacionada à Alemanha pode ser vista na Figura 6. Nota-se um aumento contínuo do PIB per capita, havendo uma exceção na transição 2008-2009, quando ocorreu a quebra da bolsa de Nova Iorque. A intensidade energética alemã diminuiu consideravelmente, mostrando que o país cresceu economicamente consumindo menos energia. Esse fato pode ser associado com a evolução das tecnologias que visam a redução do gasto energético. Houve redução da quantidade absoluta de $\mathrm{CO}_{2}$ emitido, bem como diminuição da intensidade de dióxido de carbono. Esses dados confirmam que o país tem buscado reduzir seus impactos ambientais, gerando energia com menores valores de emissão de GEE. A variação populacional é quase nula, corroborando com o fato da Alemanha ter uma baixa taxa de natalidade. 
Figura 6 - Desenvolvimento dos Índices de Kaya na Alemanha.

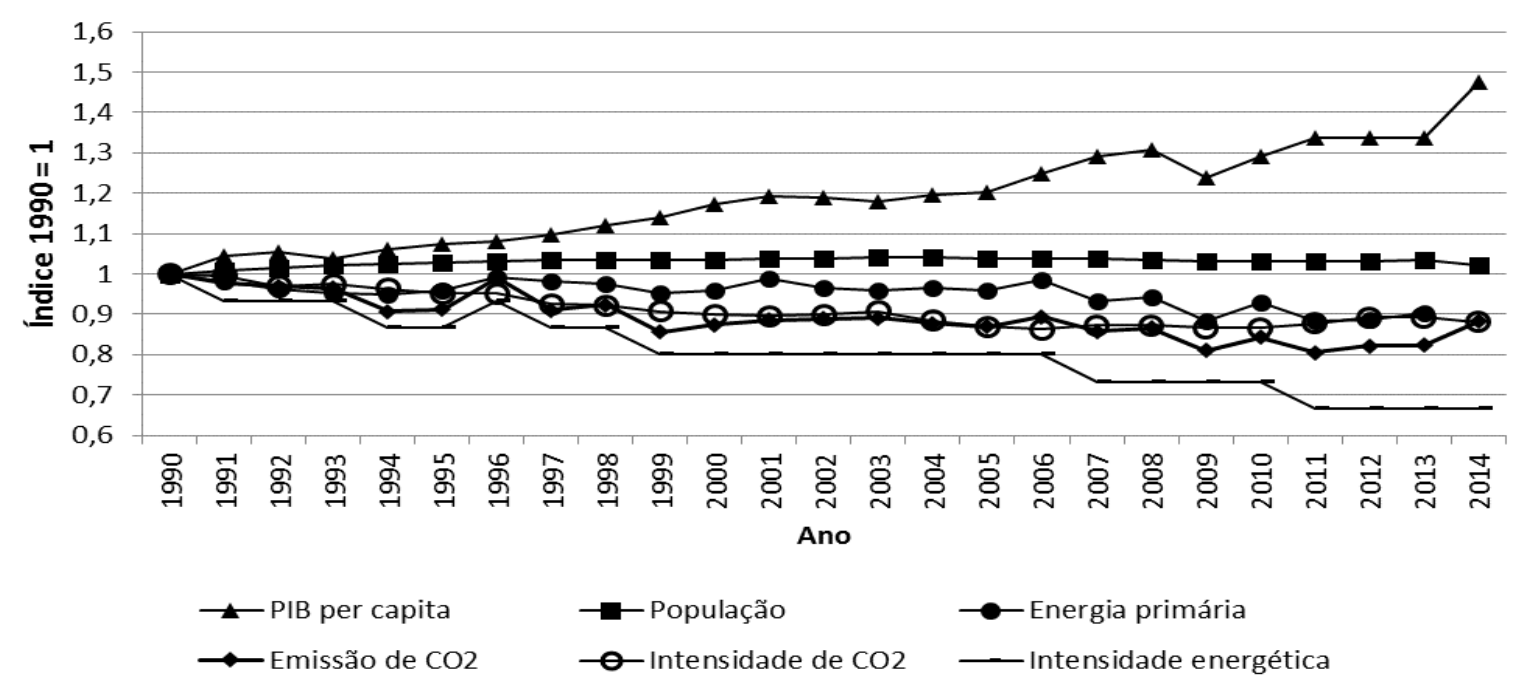

Fonte: Elaboração própria.

O cenário norte-americano é apresentado na Figura 7. Percebe-se um comportamento crescente do PIB per capita e da população. Em contrapartida, a intensidade de dióxido de carbono e energética tem aspecto decrescente. Isso mostra que o país aumenta seu poder econômico conseguindo consumir menos energia e controlando a intensidade de GEE emitidos, investindo no desenvolvimento de tecnologias limpas, como a FV.

Figura 7 - Desenvolvimento dos Índices de Kaya nos Estados Unidos.

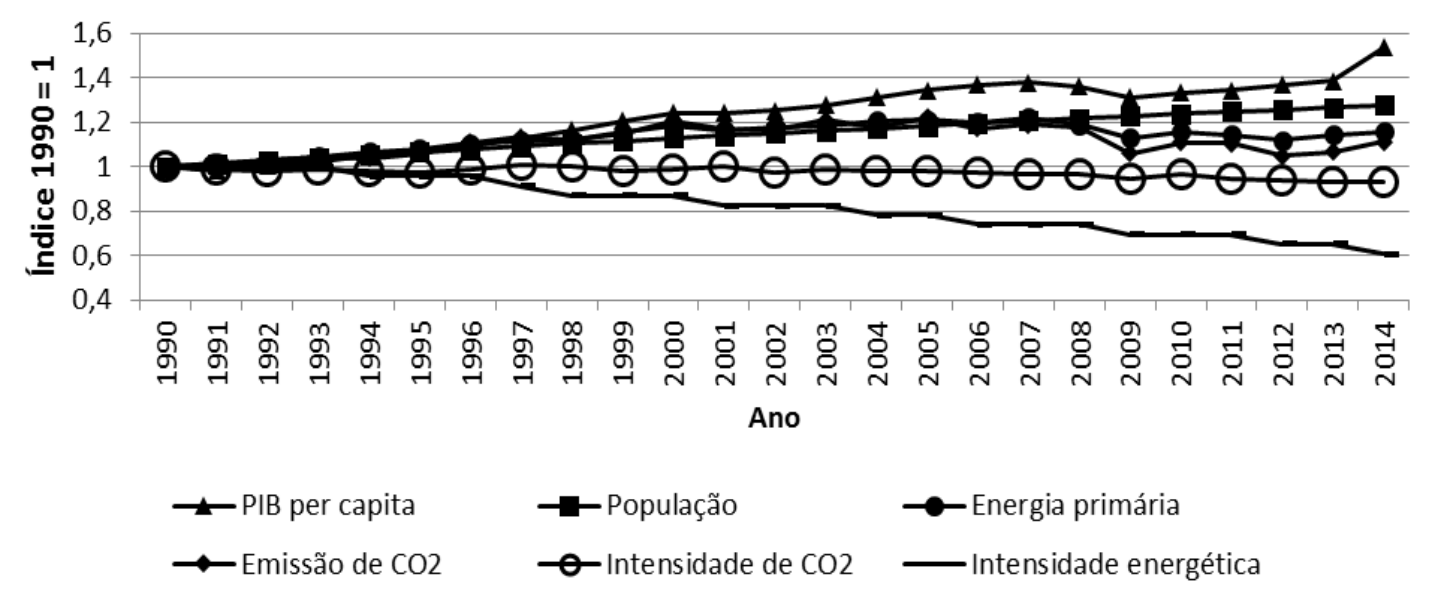

Fonte: Elaboração própria.

\subsection{Alguns dados brasileiros}

A composição da matriz elétrica mundial e brasileira possuem algumas disparidades. Schutte (2014) mostrou que 68\% da matriz elétrica mundial é obtida a partir de combustíveis fósseis - petróleo, carvão e gás natural. Em contrapartida, apenas 9,7\% da energia brasileira é gerada com fontes fósseis. Esses dados podem ser verificados na Tabela 1. Pode-se considerar, então, que a matriz elétrica do Brasil é relativamente limpa, compondo os outros 90,3\% de sua 
energia, com a utilização da energia nuclear, hidrelétrica, derivados de cana e outros. Nesse cenário se percebe que o investimento brasileiro na geração de energia FV é inferior em relação a outros países do mundo, que baseiam sua matriz energética na queima do carvão, petróleo ou gás natural. Há maior urgência dos países que se destacam negativamente na emissão de $\mathrm{CO}_{2}$, em promover uma adequação aos padrões energéticos menos agressores ao meio ambiente. Não fosse os problemas de desmatamento no Brasil, o país possuiria menores exigências de adequação aos padrões dito sustentáveis, pois sua base elétrica encontra-se nas hidrelétricas, marcando 70,6\% de toda a energia produzida no país, dado divulgado por Goldemberg (2015).

Tabela 1 - Fontes de energia responsáveis pela matriz elétrica mundial e brasileira (2010).

\begin{tabular}{|c|c|c|c|c|}
\hline & Mundo (\%) & Brasil (\%) & Mundo (GWh) & Brasil (GWh) \\
\hline Carvão* & $41,0 \%$ & $1,3 \%$ & - & - \\
\hline $\begin{array}{l}\text { Gás } \\
\text { Natural* }\end{array}$ & $22,0 \%$ & $5,7 \%$ & - & - \\
\hline Hidrelétrica & $16,0 \%$ & $74,3 \%$ & 3.529 .529 & 403.289 \\
\hline Nuclear & $13,0 \%$ & $2,7 \%$ & - & - \\
\hline Petróleo* & $5,0 \%$ & $2,7 \%$ & - & - \\
\hline $\begin{array}{l}\text { Derivados } \\
\text { de cana }\end{array}$ & $0,0 \%$ & $5,1 \%$ & - & - \\
\hline Outros & $3,0 \%$ & $8,2 \%$ & - & - \\
\hline $\begin{array}{l}\text { TOTAL DE } \\
\text { FÓSSEIS* }\end{array}$ & $68,0 \%$ & $9,7 \%$ & & \\
\hline Eólica & & & 341.274 & 2.177 \\
\hline FV & & & 32.346 & 0 \\
\hline
\end{tabular}

Fonte: Elaboração própria.

Os dados apresentados na Tabela 1 se referem ao ano-base de 2010. No ano de 2013, o Brasil já apresentava potencial eólico de 6.576 GWh (IEA, 2015). Fraunhofer (2015) afirmou que no ano de 2015 haviam 25 MWp de capacidade elétrica FV instalada em território brasileiro.

Visto os baixos valores de geração FV, o Brasil tem passado pela necessidade de alcançar patamares mais altos no desenvolvimento de tecnologia FV. Godoi (2016) informou que, conforme as regras determinadas pelo BNDES, a partir de janeiro de 2020 as células FV devem ser produzidas localmente ou em unidade própria para a tecnologia de silício cristalino. Acontece que, para atrair a atenção de empresas que realizam esse serviço, o país deve ter pelo menos $2 \mathrm{GW}$ de potência instalada contratada. Atualmente, a nação brasileira conta com $1 \mathrm{GW}$ efetivamente contratado. Sendo assim, o governo federal deverá acelerar o ritmo de contratação de projetos solares FV, caso tenha o interesse em fomentar o atendimento aos prazos do programa de nacionalização do órgão. Nesse processo, é importante que o país tenha horizontes de demanda, realizando uma prospecção de três a cinco anos a partir de 2020, de forma que se possa ter uma noção de viabilidade do negócio. Para tanto, o planejamento deve ser integrado, envolvendo o MME, BNDES, MDIC e PADIS. 
Alguns estudos expõem valores interessantes no que tange à geração de energia FV por instalação residencial nos telhados, compondo a matriz elétrica brasileira. Dados do MME mostraram o potencial desse tipo de geração em telhados residenciais. Os estados de São Paulo e Minas Gerais apresentam essa maior capacidade, com potencial de gerar eletricidade com sistemas FV instalados nos telhados, entre 70 e $170 \mathrm{GWh}$ por dia.

Ainda que o país possua alto potencial para geração FV, algumas análises de emissões de GEE devem ser realizadas. A Identidade de Kaya foi utilizada como ferramenta de análise das emissões brasileiras. Em uma análise da Figura 8, percebe-se o forte acoplamento entre o consumo de energia e as emissões de $\mathrm{CO}_{2}$ no Brasil, ambos mantendo um padrão de crescimento na maior parte da linha do tempo considerada. A intensidade energética manteve-se relativamente constante, significando que o país cresce economicamente consumindo quantidade proporcional de energia. $\mathrm{O}$ comportamento crescente das linhas mostra a característica marcante de países em desenvolvimento. Eles se desenvolvem emitindo mais $\mathrm{CO}_{2}$.

Figura 8 - Desenvolvimento dos Índices de Kaya no Brasil.

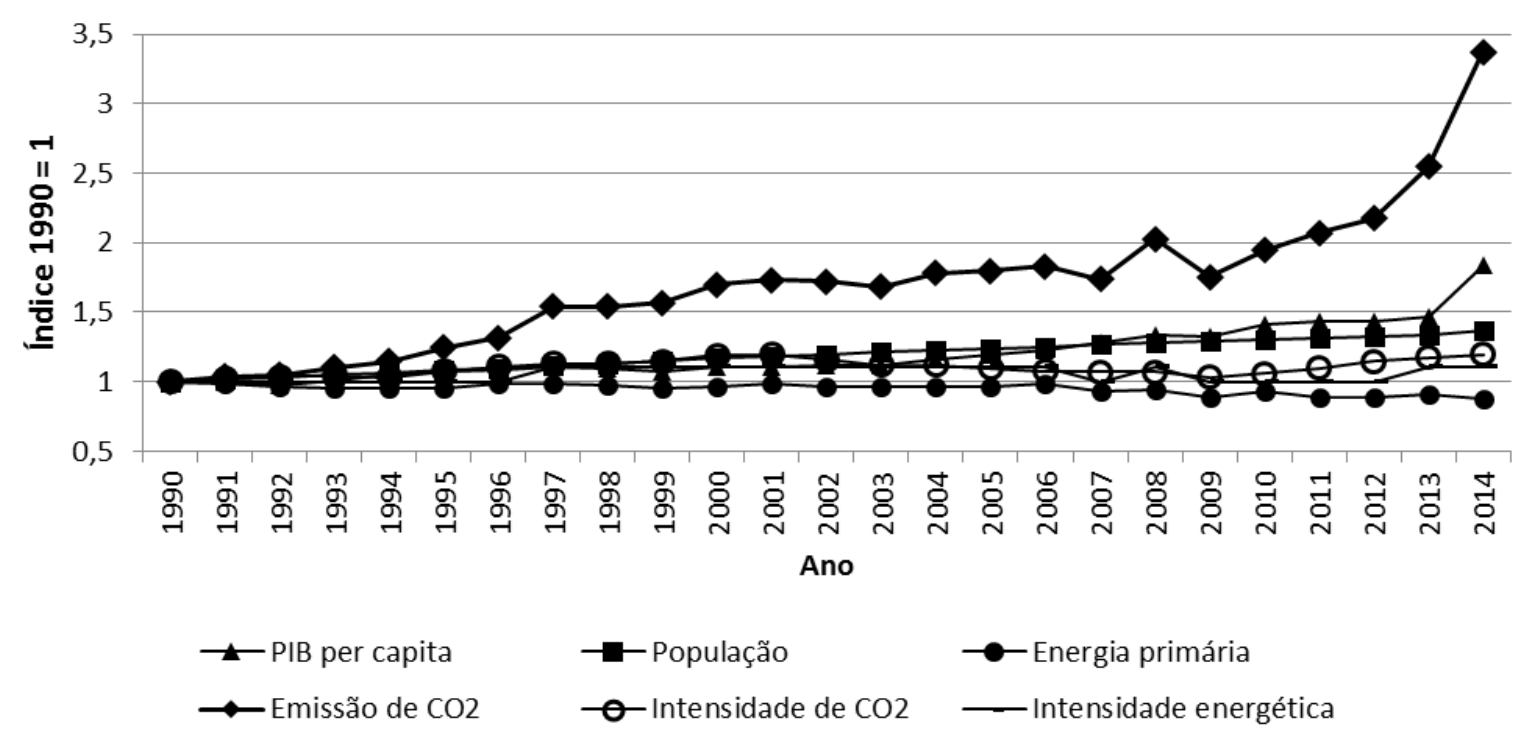

Fonte: Elaboração própria.

Algumas informações supracitadas são corroboradas na Figura 9. Realizando um corte temporal de 1990 a 2013, o Brasil não se destacou positivamente quanto à intensidade de emissão de $\mathrm{CO}_{2}$. $\mathrm{O}$ valor absoluto de dióxido de carbono liberado aumentou consideravelmente na faixa de tempo considerada. A Itália e Alemanha diminuíram esse valor. Os outros países praticamente mantiveram a quantidade de gás emitido por queima de combustíveis fósseis.

Constata-se também que o Brasil se desenvolveu economicamente emitindo mais GEE (movimento vertical para cima), diferente dos outros países. Todos os outros apresentaram deslocamento em direção ao vértice do gráfico, demonstrando um desenvolvimento econômico com menor intensidade de emissões. A movimentação vertical ascendente é comumente observada nos países que se encontram em desenvolvimento. Em contrapartida, os países desenvolvidos conseguem crescer economicamente emitindo menos GEE.

Por fim, nota-se que a emissão per capita aumentou no Brasil (movimento horizontal para a direita), diferindo-se de todos os outros países, excetuando o Japão. A Itália, Alemanha, Espanha e 
Estados Unidos apresentaram um crescimento populacional emitindo menos $\mathrm{CO}_{2}$. Apesar do Brasil ter grande potencial para as energias eólica e $\mathrm{FV}$, o país ainda não atingiu o patamar ideal em avanço tecnológico nessas vertentes. Tomando como premissa que tanto a população quanto o PIB de um país tendem a aumentar no passar dos anos, a nação brasileira deve investir na evolução dessas fontes energéticas para reduzir a taxa de emissão per capita.

O Brasil possui um baixo valor bruto de emissão de GEE, se comparado com o cenário mundial. A população norte-americana é $58 \%$ maior do que a brasileira. No entanto, a emissão de $\mathrm{CO}_{2}$ nos Estados Unidos é $1032 \%$ maior do que a emitida no Brasil (ver Figura 9). Pode-se concluir que a nação brasileira possui uma matriz energética pouco poluidora. A grande questão está na direção que o país se movimenta, com aumento de emissões per capita, e um desenvolvimento econômico também com maiores emissões.

Figura 9 - Intensidade de emissão de $\mathrm{CO}_{2}$.

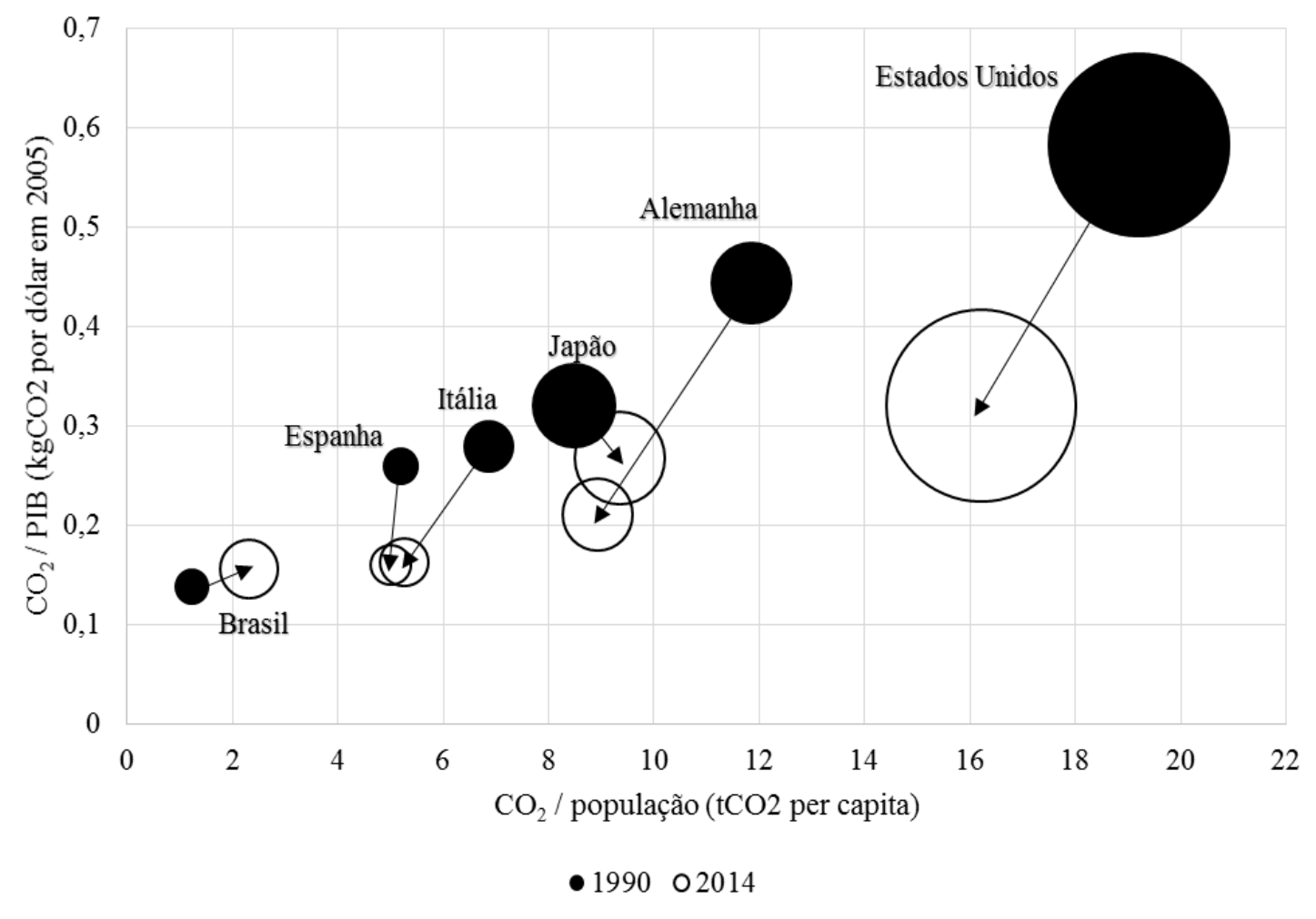

Fonte: Elaboração própria.

\subsection{Perspectivas para os próximos anos}

Magnus et al. (2016), em trabalho recente, obtiveram dois valores de previsão para a potência instalada brasileira no setor FV: 3,495 GWp em um cenário conservador e 17,32 GWp, de forma mais otimista. A queda do preço dos sistemas FV é iminente, conforme previsões realizadas em estudos científicos do MME (2014). Dessa forma, o fenômeno de desacoplamento entre as emissões de $\mathrm{CO}_{2}$ e o desenvolvimento econômico se acentuará, assim que o preço dos módulos FV atingirem a classe $\mathrm{C}$ da sociedade, acompanhando a curva de aprendizagem das novas tecnologias.

Esse efeito de separação das curvas foi demonstrado por Freitas e Kaneko (2011), numa análise das emissões brasileiras. Os autores observaram que houve uma acentuada mudança de direção entre as emissões de dióxido de carbono e o crescimento econômico brasileiro, de 2004 a 2009. Eles associaram esse fenômeno à diversificação de energias renováveis utilizadas no Brasil, 
assim como com outros fatores, tal como a utilização do etanol como combustível automobilístico. Zhang e Da (2015) estudaram o mesmo fenômeno na China, associando sua ocorrência à diminuição da intensidade energética, redução da utilização do carvão mineral, otimização da utilização do carvão, e implementação da tecnologia carvão limpo.

A IEA (2016) publicou informações sobre o desacoplamento existente entre o crescimento econômico mundial e as emissões de $\mathrm{CO}_{2}$. Esse efeito foi analisado por Lima, Machado e Rangel (2016). A agência internacional informou que o total de emissões em 2015 se manteve estável em relação ao ano de 2014. A Figura 10 mostra essa dissociação, considerando o período de 1990 a 2014.

Figura 10 - Desacoplamento no mundo entre as emissões de $\mathrm{CO}_{2}$ per capita $\left(\mathrm{tCO}_{2}\right)$ e PIB (1 bilhão de dólares americanos em 2005).

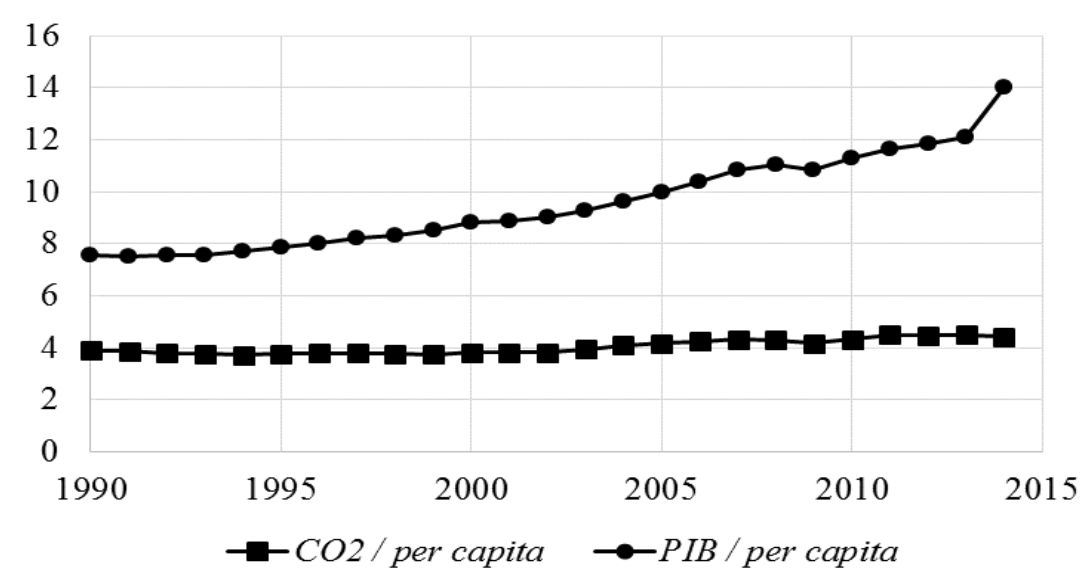

Fonte: Elaboração própria.

A tendência é que essas curvas se separem mais, a partir do momento em que os sistemas FV e eólicos cheguem à classe $\mathrm{C}$ da sociedade. Um fato é certo: esse decaimento somente ocorrerá com o auxílio governamental, que deverá fomentar a evolução tecnológica por intermédio de incentivos fiscais, assim como ocorreu com o etanol. Quando isso ocorrer, a geração de eletricidade por fontes renováveis promoverá uma maior queda das emissões, e permitirá que o crescimento da economia no mundo aconteça de forma menos poluidora. Para tanto, é mister que os investimentos governamentais atuem no desenvolvimento das tecnologias de aproveitamento das fontes nãofósseis, trazendo resultados favoráveis para a sociedade e o meio em que ela vive.

A Figura 11 traz a Identidade de Kaya aplicada para as emissões de $\mathrm{CO}_{2}$, com dados atualizados até 2015, em escala global (IEA, 2016). Nota-se a estabilização das emissões nos últimos dois anos. A expectativa é que esses valores permaneçam estáveis ou diminuam, considerando as intensas investidas no setor energético renovável. Mesmo com a estabilização da emissão de dióxido de carbono, o PIB mundial continua crescendo, como já demonstrado na Figura 10. A queda da curva em 2008 é justificada pela crise econômica mundial. No entanto, no período 2014-2015 não se verifica a existência de nenhuma crise no cenário global.

Figura 11 - Identidade de Kaya aplicada para as emissões de $\mathrm{CO}_{2}$ a nível mundial, contemplando os anos de 1990 a 2015. 


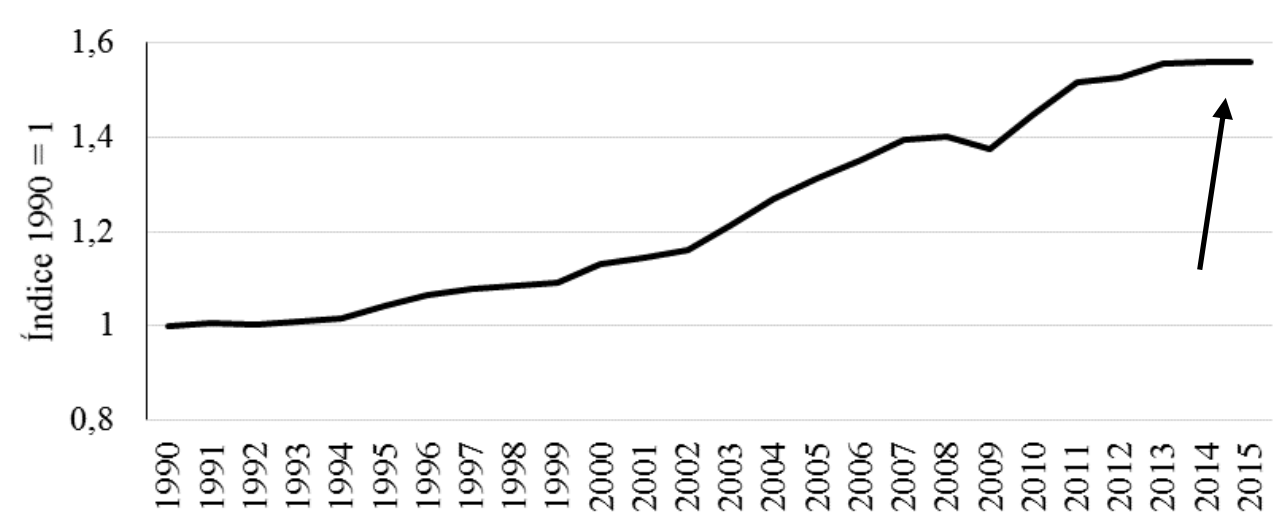

\section{CONSIDERAÇÕES FINAIS}

Fonte: Elaboração própria.

A geração de energia fotovoltaica foi analisada considerando a Alemanha, Itália, Japão, Estados Unidos e Espanha. Percebeu-se o domínio da Alemanha e Itália no setor, com fortes investimentos no desenvolvimento e disseminação dessa tecnologia. Os Estados Unidos se destacou no cenário eólico, ultrapassando a Alemanha em 2007. Nesse cenário, o Brasil aparece superando o Japão em 2012.

Apesar da nação brasileira apresentar destaque nas energias renováveis, portando uma matriz energética relativamente limpa em relação ao cenário mundial, ele continua tendo emissão de $\mathrm{CO}_{2}$ per capita com comportamento crescente. Ou seja, o país deve explorar seu potencial de utilização de energias renováveis, tais como a fotovoltaica e eólica, para reduzir suas taxas de emissão. Vale notificar que a nação brasileira possui características geográficas favoráveis para a implantação dessas tecnologias. A Alemanha, Estados Unidos, Espanha e Itália se diferem nessas características, mostrando controle sobre suas emissões. O cenário brasileiro corrobora com o fato de se tratar de um país em desenvolvimento, que em geral emite mais dióxido de carbono no processo de desenvolvimento.

Os gráficos de Kaya indicam as diferenças entre países desenvolvidos e os considerados em desenvolvimento. No caso brasileiro, as funções de emissão de $\mathrm{CO}_{2}$ e energia primária ascendem em conjunto, diferindo da Alemanha e Estados Unidos, que demonstraram comportamento decrescente. Mesmo assim, constatou-se que os investimentos brasileiros em formas de se utilizar energias renováveis estão em ascensão. No cenário eólico, o país já aparece nas bases de dados internacionais, com capacidade instalada superior ao do Japão. No setor fotovoltaico, as perspectivas para o futuro são promissoras, com previsão de investimentos por parte do governo federal para acelerar o aumento da capacidade instalada. Nessa perspectiva, o efeito de desacoplamento das curvas de emissões de gases do efeito estufa e desenvolvimento econômico tende a se acentuar, levando o cenário global a um estado de redução de impactos ambientais.

\section{REFERÊNCIAS}

ABRAMOVAY, R. Inovações para que se democratize o acesso à energia, sem ampliar as emissões. Ambiente \& Sociedade, v. 17, n. 3, p. 01-18, set. 2014.

ALVIM, A. M.; SANTIN, M. F. C. DE L. Os impactos do crescimento econômico sobre o aquecimento terrestre: A contribuição dos países em desenvolvimento. Estudos do CEPE, n. 26, p. 5-29, 2008 a.

ALVIM, A. M.; SANTIN, M. F. C. DE L. Os Impactos da Demanda por Crédito de Carbono sobre o Mercado de Certificações de Reduções de Emissões no Brasil. XLVI Congresso da Sociedade Brasileira de Economia, Administração e Sociologia Rural. Anais...Rio Branco, AC: jul. 2008b 
DI SANTO, K. G. et al. A review on smart grids and experiences in Brazil. Renewable and Sustainable Energy Reviews, v. 52, p. 1072-1082, dez. 2015.

DIDONÉ, E. L.; WAGNER, A.; PEREIRA, F. O. R. Strategies towards Net Zero Energy Office Buildings in Brazil with emphasis on BIPV. Ambiente Construído, v. 14, n. 3, p. 27-42, 2014.

EPE, N. T. Análise da inserção da geração solar na matriz elétrica brasileira. Nota Técnica da EPE, Rio de Janeiro, 2012.

EPIA. Global Market Outlook for Photovoltaics 2014-2018. EPIA report, p. 1-60, 2014.

FRAUNHOFER, I. Current and Future Cost of Photovoltaics: Long-term Scenarios for Market Development, System Prices and LCOE of Utility-Scale PV Systems, p. 1-82, fev. 2015.

FREITAS, L. C. DE; KANEKO, S. Decomposing the decoupling of CO2 emissions and economic growth in Brazil. Ecological Economics, v. 70, n. 8, p. 1459-1469, jun. 2011.

GAVIRIA, L. R.; PEREIRA, F. O. R.; MIZGIER, M. O. Influência da configuração urbana na geração fotovoltaica com sistemas integrados às fachadas. Ambiente Construído, v. 13, n. 4, p. 7-23, 2013.

GODOI, M. CanalEnergia | Brasil precisa acelerar contratação de solar para atrair fabricantes de células. Disponível em: <canalenergia.com.br>. Acesso em: 7 ago. 2016.

GOLDEMBERG, J. O estado atual do setor elétrico brasileiro. Revista USP, n. 104, p. 37-44, 2015.

IEA. CO2 Emissions From Fuel Combustion: IEA Statistics. Paris, France: International Energy Agency, 2015.

IEA. Decoupling of global emissions and economic growth confirmed. Disponível em: <http://www.iea.org/newsroomandevents/pressreleases/2016/march/decoupling-of-global-emissions-and-economicgrowth-confirmed.html>. Acesso em: 21 ago. 2016.

KAYA, Y.; YOKOBORI, K. (EDS.). Environment, energy, and economy: strategies for sustainability. Tokyo ; New York: United Nations University Press, 1997.

LANGE, W. J. Metodologia de mapeamento da área potencial de telhados de edificações residenciais no Brasil para fins de aproveitamento energético fotovoltaico. Rio de Janeiro: Terragis, 2012.

LIMA, Y. R. DE S.; MACHADO, T. S.; RANGEL, J. J. DE A. Desacoplamento entre as Emissões de CO2 e o PIB. Revista Produção e Desenvolvimento, v. 2, n. 3, p. 37-53, dez. 2016.

LUCON, O.; GOLDEMBERG, J. Crise financeira, energia e sustentabilidade no Brasil. Estudos Avançados, v. 23, n. 65 , p. 121-130, 2009.

MAABEN, M.; RÜBSAMEN, M.; PEREZ, A. Photovoltaic solar energy in Spain. International Finance and Economics, Seminar Papers in International Finance and Economics. 2011.

MACHADO, C. T.; MIRANDA, F. S. Photovoltaic Solar Energy: A Briefly Review. Revista Virtual de Química, v. 7, n. 1, 2015.

MAGNUS, D. DE M.; TAVARES, A. A.; BECKER, D. P. ESTUDO DA INSERÇÃO DE USINAS FOTOVOLTAICAS NA MATRIZ ELÉTRICA BRASILEIRA - 2015-2050. Revista Vincci - Periódico Científico da Faculdade SATC, v. 1, n. 1, p. 75-98, 4 ago. 2016.

MME (ED.). Inserção da Geração Fotovoltaica Distribuída no Brasil - Condicionantes e Impactos. Inserção da Geração Fotovoltaica Distribuída no Brasil - Condicionantes e Impactos, out. 2014.

SACHS, I. A revolução energética do século XXI. Estudos avançados, v. 21, n. 59, p. 21-38, 2007.

SCHUTTE, G. R. Energia e desenvolvimento sustentável no Brasil - Trajetórias recentes e perspectivas. ago. 2014.

ZHANG, Y.-J.; DA, Y.-B. The decomposition of energy-related carbon emission and its decoupling with economic growth in China. Renewable and Sustainable Energy Reviews, v. 41, p. 1255-1266, jan. 2015. 